\title{
Synthesis and Characterization of
}

\section{Aminopropylsilane-Polydopamine Coatings}

Daniel B. Knorr, Jr., ${ }^{\dagger}$ Ngon Tran ${ }^{\dagger}$, Karen J. Gaskell,,${ }^{\ddagger}$ Joshua A. Orlicki, ${ }^{\dagger}$ Joseph C. Woicik, ${ }^{\S}$ Daniel A. Fischer ${ }^{\S}$ Joseph L. Lenhart ${ }^{\dagger}$

$\dagger$ U.S. Army Research Laboratory, Aberdeen Proving Ground, Maryland, United States

Department of Chemistry and Biochemistry, University of Maryland College Park, College

Park, Maryland, United States

${ }^{\S}$ Material Science and Engineering Laboratory, National Institute of Standards and Technology, Gaithersburg, Maryland, United States 


\section{Microscope Images}

Optical microscopy images (15x magnification) of several of the coatings deposited after 7.5 hours are shown in Figure S1 below. These images are in qualitative agreement with a model of polydopamine deposition suggested previously. ${ }^{1}$

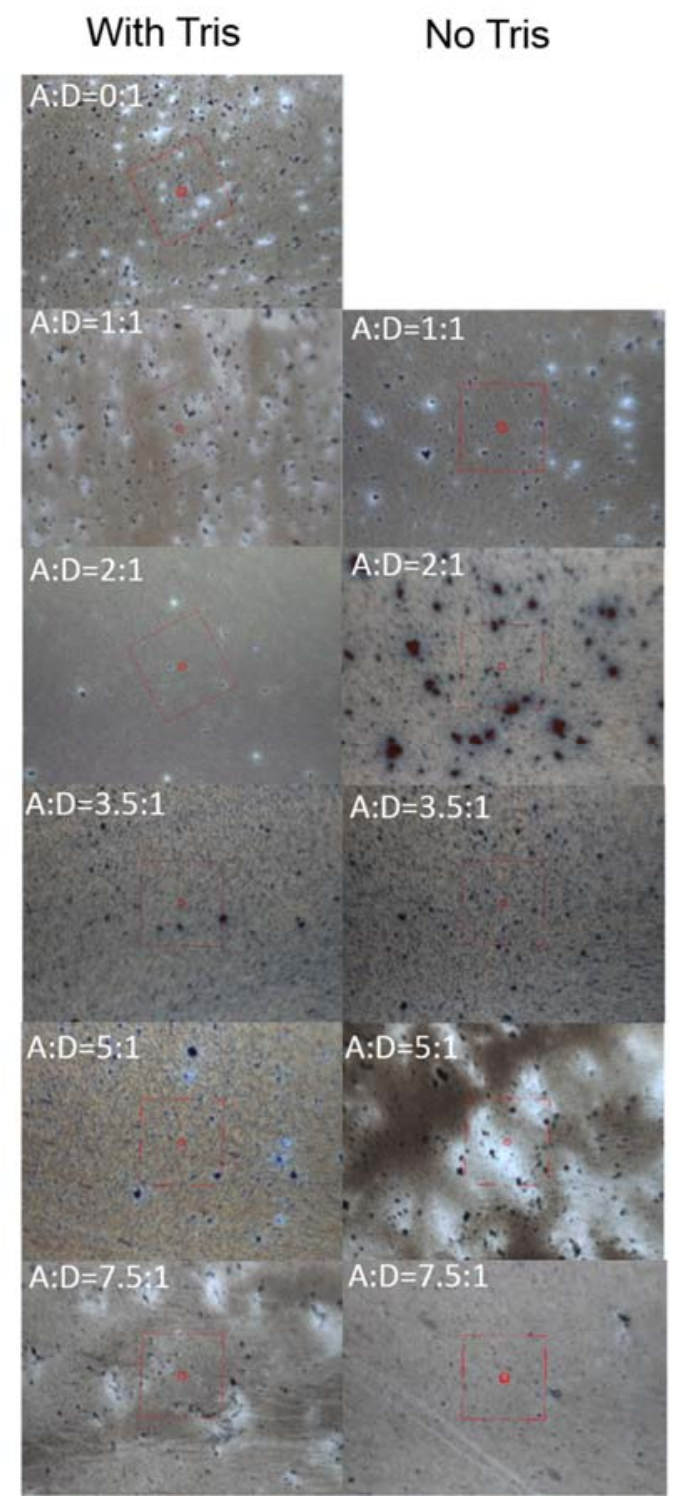

Figure S1. Microscopy images of polydopamine-aminopropyltriethoxysilane coatings deposited for 7.5 hours. 


\section{VASE Fitting}

Precise determination of the thickness of the coatings from VASE is difficult due to the surface roughness that occurs during coating. Therefore, to estimate the coating thickness for the various coatings, two general models were used to fit the VASE data obtained for each sample and the model that gave the better fit (i.e., lower mean squared error) was chosen. The first model was composed of a base layer of silicon ( $1 \mathrm{~mm}$ thick), with a silicon oxide layer (generally 2-3nm thick) measured from the bare wafers used, and a Cauchy layer. For the coatings rich in PDA (i.e., A:D=0:1, 1:1, 2:1, 3.5:1, 5:1, 7.5:1), the Cauchy layer was based on literature data for polydopamine $^{2}$ and values of $\mathrm{A}=1.73, \mathrm{~B}=0.01, \mathrm{C}=0$ were employed with a $\mathrm{k}$ amplitude of 0.022 , an exponent of 1.5 and a band edge of $632.8 \mathrm{~nm}$. For coatings rich in APTES (i.e., A:D=10:1 and 0:1) the Cauchy layer was taken to be that for APTES ${ }^{3}$. For this first model, the thickness of the Cauchy layer was varied to fit the data, and this model gave the best fit for most coatings at deposition times $\leq 2.5 \mathrm{~h}$, which were generally more uniform to the naked eye.

For most samples at deposition times of $5 \mathrm{~h}$ and above, the roughness of the surface during deposition was accounted for using a second model in which a Bruggeman effective medium approximation (EMA) layer composed of the Cauchy layer mentioned above and void was added to the first model. In these cases, the thickness of the main Cauchy layer, the thickness of the EMA layer and the void content in the EMA layer were varied to fit the data. The reported thickness is the sum of the main Cauchy layer thickness plus the Cauchy content of the EMA layer times the thickness of the EMA layer.

The mean squared error (MSE) of all the fits are provided in Fig. S1. For reference, values of $<15$ provided excellent fits of the data, while poor fitting was observed for MSE values 
greater than about 30. As shown in Fig. S4, the MSE generally increased with increasing deposition time, which also corresponded to an overall increase in visible surface roughness.
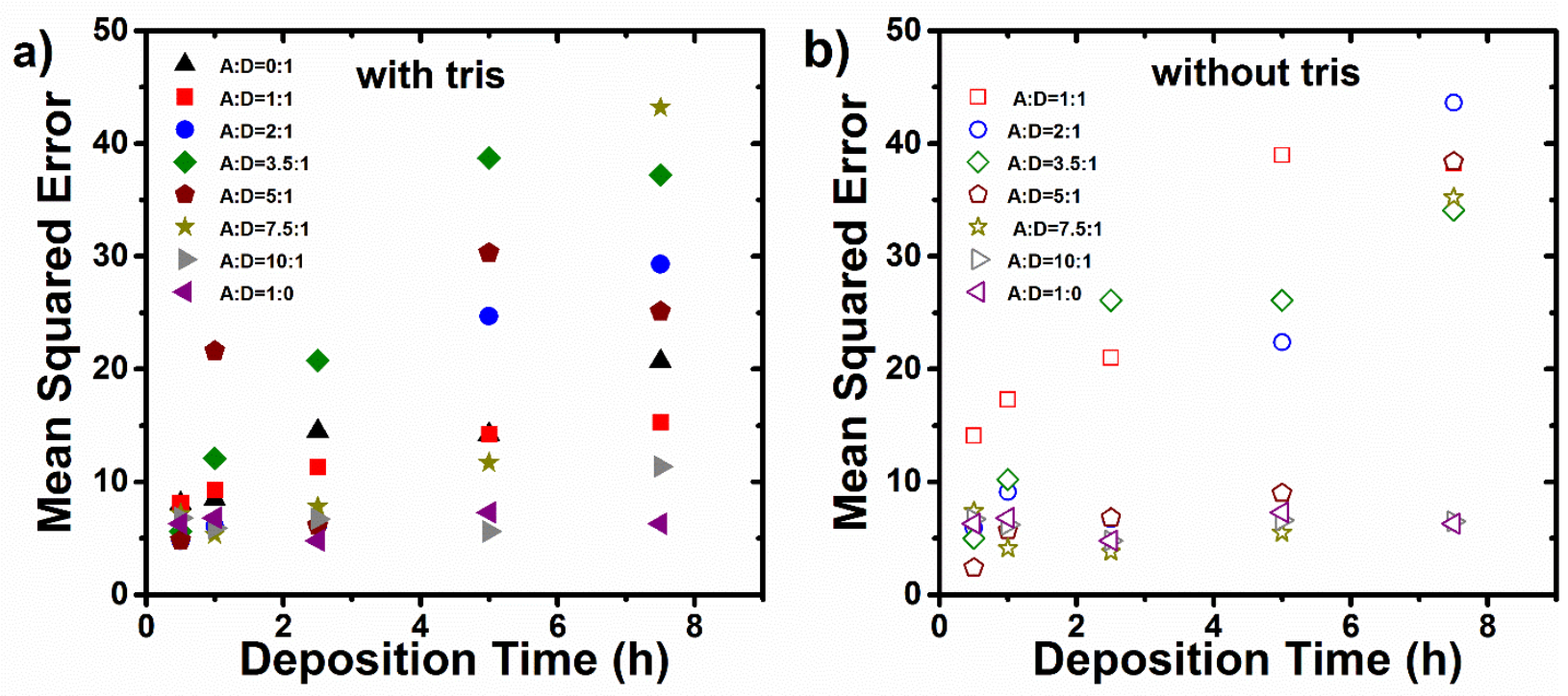

Figure S2. Mean squared error of VASE fits as a function of deposition time.

\section{Fitting of XPS Data}

XPS peak fitting for conventional XPS data was performed using the CasaXPS software. Table $\mathrm{S} 1$ provides the binding energies used for fitting individual species of $\mathrm{C}, \mathrm{N}$, and $\mathrm{O}$ as well as references for similar use of these fits.

C 1s. Peaks of C 1s, Fig. S2 were fit using peaks of equal FWHM (1.6) for C-C, C=O, and C$\mathrm{N} / \mathrm{C}-\mathrm{O} / \mathrm{C}=\mathrm{N}$ based on best fits obtained for the whole data set. The FWHM of the $\pi \rightarrow \pi *$ shake-up peak was allowed to vary. Peak positions were generally $284.8 \mathrm{eV}$ for C-C, $286.3 \mathrm{eV}$ for $\mathrm{C}-\mathrm{N} / \mathrm{C}-\mathrm{O} / \mathrm{C}=\mathrm{N}$, and $288.2 \mathrm{eV}$ for $\mathrm{C}=\mathrm{O}$, and the latter two were allowed to vary during fitting, but did not change more than $0.2 \mathrm{eV}$ for any dataset. The peak position for the $\pi \rightarrow \pi *$ shake-up peak was allowed to vary, but was close to $290.5 \mathrm{eV}$ for all cases where it was observed. 
Table S1. XPS peak assignments and binding energies.

\begin{tabular}{|c|c|c|c|}
\hline & Species & $\begin{array}{l}\mathrm{BE} \\
(\mathrm{eV})\end{array}$ & References \\
\hline \multirow[t]{4}{*}{$\mathrm{C} 1 \mathrm{~s}$} & $\mathrm{C}-\mathrm{C} / \mathrm{C}-\mathrm{H} / \mathrm{C}-\mathrm{Si}$ & 284.8 & 4,5 \\
\hline & $\mathrm{C}-\mathrm{O} / \mathrm{C}-\mathrm{N} / \mathrm{C}=\mathrm{N}$ & 286.3 & 6,7 \\
\hline & $\mathrm{C}=\mathrm{O}$ & 288.2 & 4-7 \\
\hline & $\pi \rightarrow \pi^{*}$ shake up & 290.5 & 6,7 \\
\hline \multirow[t]{3}{*}{$\mathrm{N}$ 1s } & Aromatic N & 398.5 & 6-8 \\
\hline & $\mathrm{R}_{2} \mathrm{NH} / \mathrm{RNH}_{2}$ & 399.8 & $4,5,7-10$ \\
\hline & $\mathrm{C}-\mathrm{NH}_{3}{ }^{+}$ & 401.7 & $4,5,10$ \\
\hline \multirow[t]{4}{*}{$\mathrm{O} 1 \mathrm{~s}$} & $\mathrm{O}-\mathrm{C}$ & 532.9 & 6,11 \\
\hline & $\mathrm{O}=\mathrm{C}$ & 531.3 & 6,12 \\
\hline & $\mathrm{O}-\mathrm{Si}$ & 532.2 & 13 \\
\hline & $\mathrm{H}_{2} \mathrm{O}$ & 535.5 & 6 \\
\hline \multirow[t]{2}{*}{ Si $2 p$} & $\mathrm{O}_{3}-\mathrm{Si}-\mathrm{C}$ (APTES) & 102.4 & 14 \\
\hline & $\begin{array}{l}\mathrm{HO}_{3}-\mathrm{Si}-\mathrm{C} \\
\text { (APTES/base) }\end{array}$ & 102.9 & 14 \\
\hline
\end{tabular}

$\underline{\mathrm{O} 1 \mathrm{~s}}$. Spectra for $\mathrm{O} 1 \mathrm{~s}$ were fit with up to four peaks. Peaks associated with $\mathrm{O}-\mathrm{C}$ and $\mathrm{O}=\mathrm{C}$ were fit with peaks of a FWHM of $1.8 \mathrm{eV}$ based on best fits obtained for the whole data set. The O-C peak $(\sim 532.9 \mathrm{eV})$ was allowed to move position in terms of binding energy during fitting, but the $\mathrm{O}=\mathrm{C}$ peak position was constrained to be $1.6 \mathrm{eV}$ below the $\mathrm{O}-\mathrm{C}$ peak $(\sim 531.3 \mathrm{eV})$. Several of the samples showed broad peaks at higher binding energy that are characteristic of residual water. The water peak was allowed to vary in position and FWHM during fitting. Finally, an O-Si peak was used to fit condensed silanols in the coating from APTES. The O-Si peak position $(\sim 532.2$ eV) was allowed to vary during fitting, but the FWHM was fixed to $60 \%$ of that of the value for the $\mathrm{O}-\mathrm{C}$ and $\mathrm{O}=\mathrm{C}$ peaks.

$\underline{\mathrm{N} 1 \mathrm{~s} .}$ Spectra for N 1s are shown in Figure S4 and were fit using three peaks. The FWHM values of all the peaks were $1.7 \mathrm{eV}$ based on the best fits obtained for the whole data set. Three peaks were used to fit the data corresponding to $\mathrm{NH}$ (indole rings), $\mathrm{R}_{2} \mathrm{NH} / \mathrm{RNH}_{2}$ and $-\mathrm{NH}_{3}{ }^{+} /$hydrogen 
bonded nitrogen at $\sim 398.5 \mathrm{eV}, \sim 399.8 \mathrm{eV}$, and $\sim 401.7 \mathrm{eV}$, respectively. Here, the peak fits were constrained such that the $\mathrm{R}_{2} \mathrm{NH} / \mathrm{RNH}_{2}$ position could vary, but the aromatic $\mathrm{NH}$ and the $-\mathrm{NH}_{3}{ }^{+}$/ hydrogen bonded nitrogen peaks were $1.3 \mathrm{eV}$ lower and $1.9 \mathrm{eV}$ higher than the $\mathrm{R}_{2} \mathrm{NH} / \mathrm{RNH}_{2}$ peak, respectively, for all fits. There were four exceptions to this, namely the APTES only $(A: D=1: 0)$ and the $A: D=10: 1$ samples deposited with or without tris. For these, the general shape of the curve resembled that of APTES only, which has peaks associated with free amine and hydrogen bonded amine. The FWHM of all peaks for these four samples was $1.3 \mathrm{eV}$ based on best fits obtained for the whole data set. Note that imine peaks were not specifically fit in the samples, although the NEXAFS data below suggest they are present to some extent. Imine peaks should be $\sim 0.5 \mathrm{eV}$ higher than the corresponding free amine and protonated amines ${ }^{15}$, and may be buried in the stronger amine peaks.

$\underline{\text { Si } 2 p}$. Spectra for Si $2 p$ are shown in Figure S3 and were fit using up to three peaks for samples where the substrate Si signal was not dominant (i.e., A:D=1:1, 2:1, 3.5:1, 5:1, 7.5:1). 


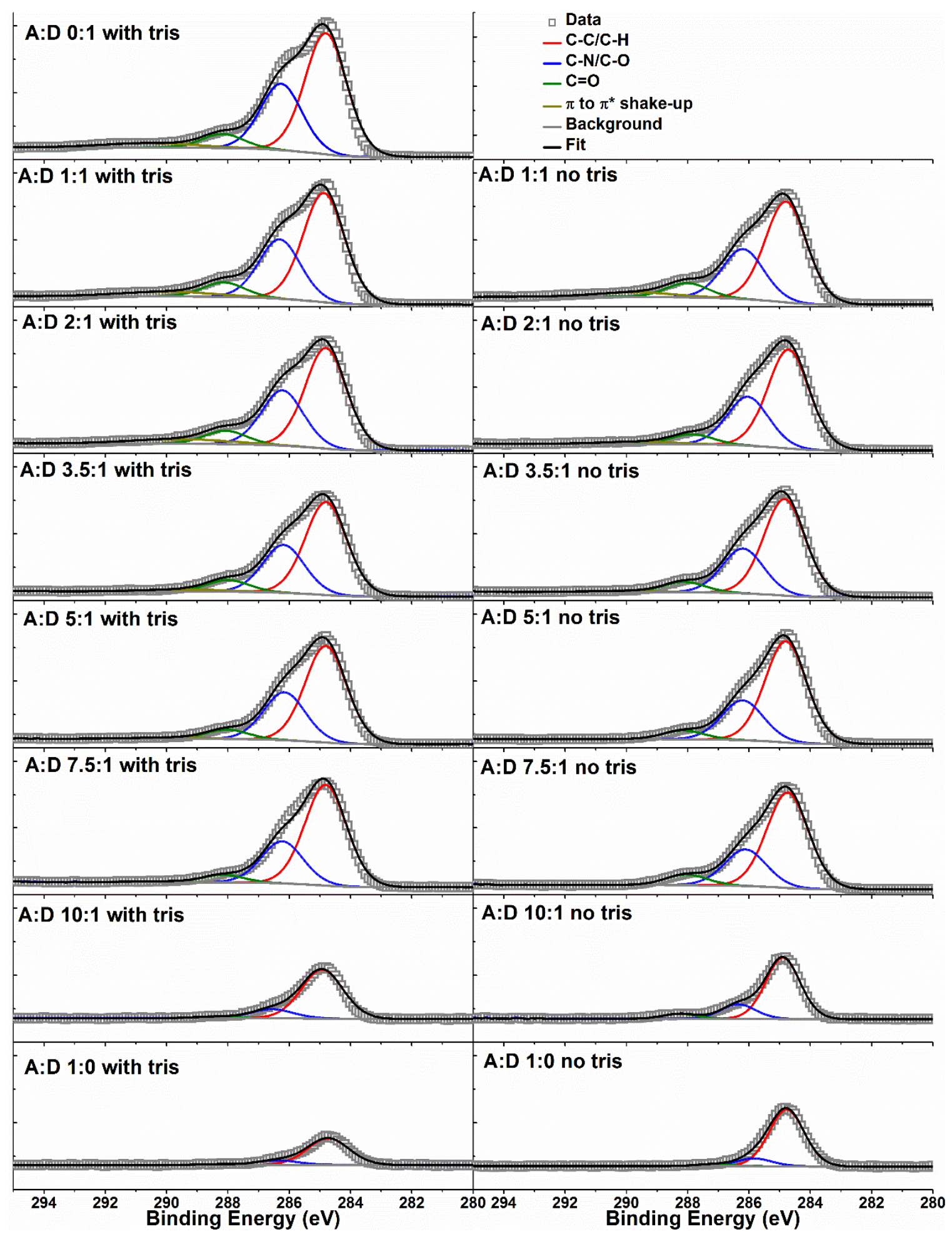

Figure S3. C 1s XPS spectra of all APTES-PDA coatings deposited at different A:D ratios. The $\mathrm{y}$-axis is in CPS and all y-scales are identical. 


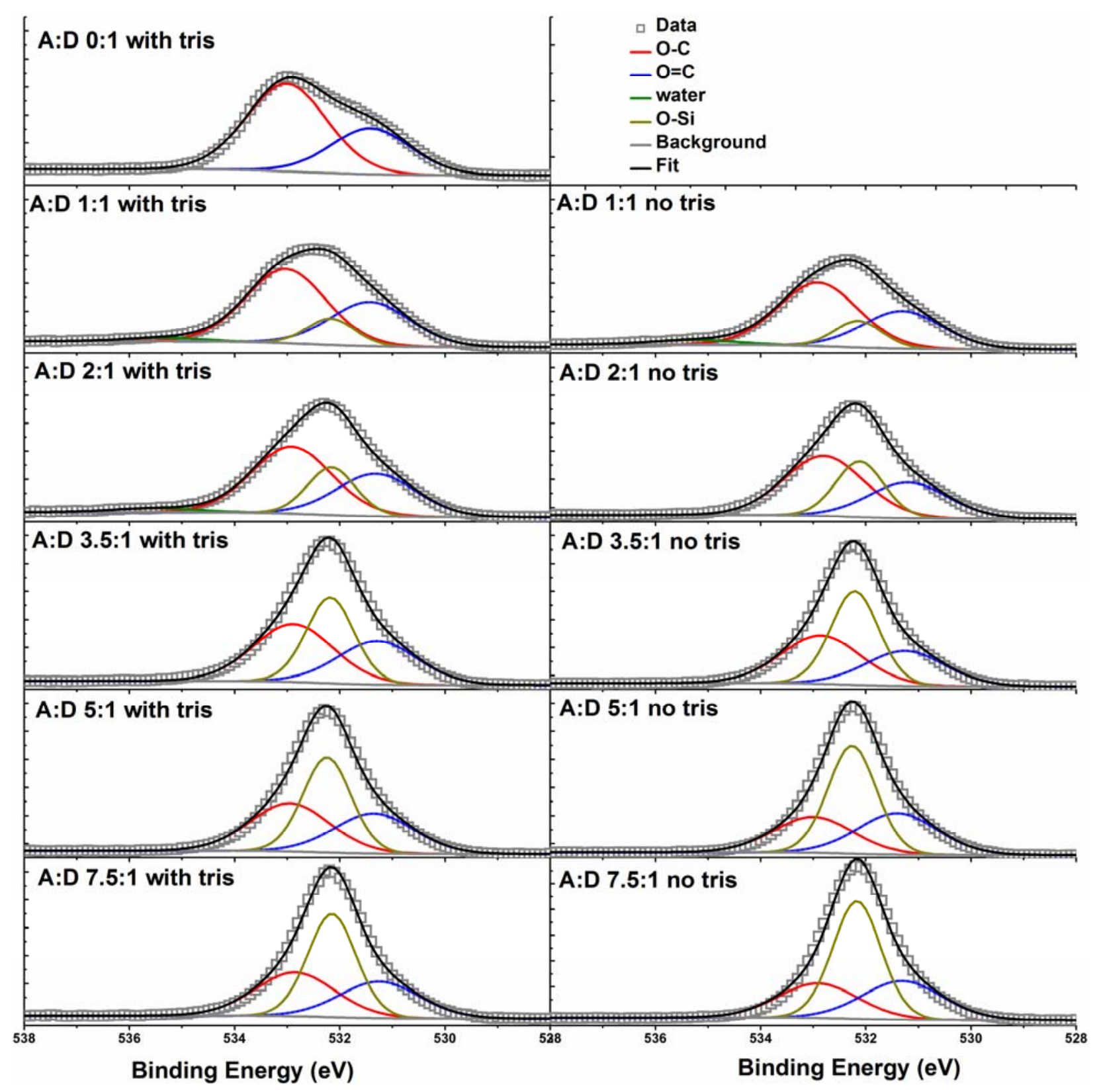

Figure S4. O 1s XPS spectra of all APTES-PDA coatings deposited at different A:D ratios. The $\mathrm{y}$-axis is in CPS and all y-scales are identical. 


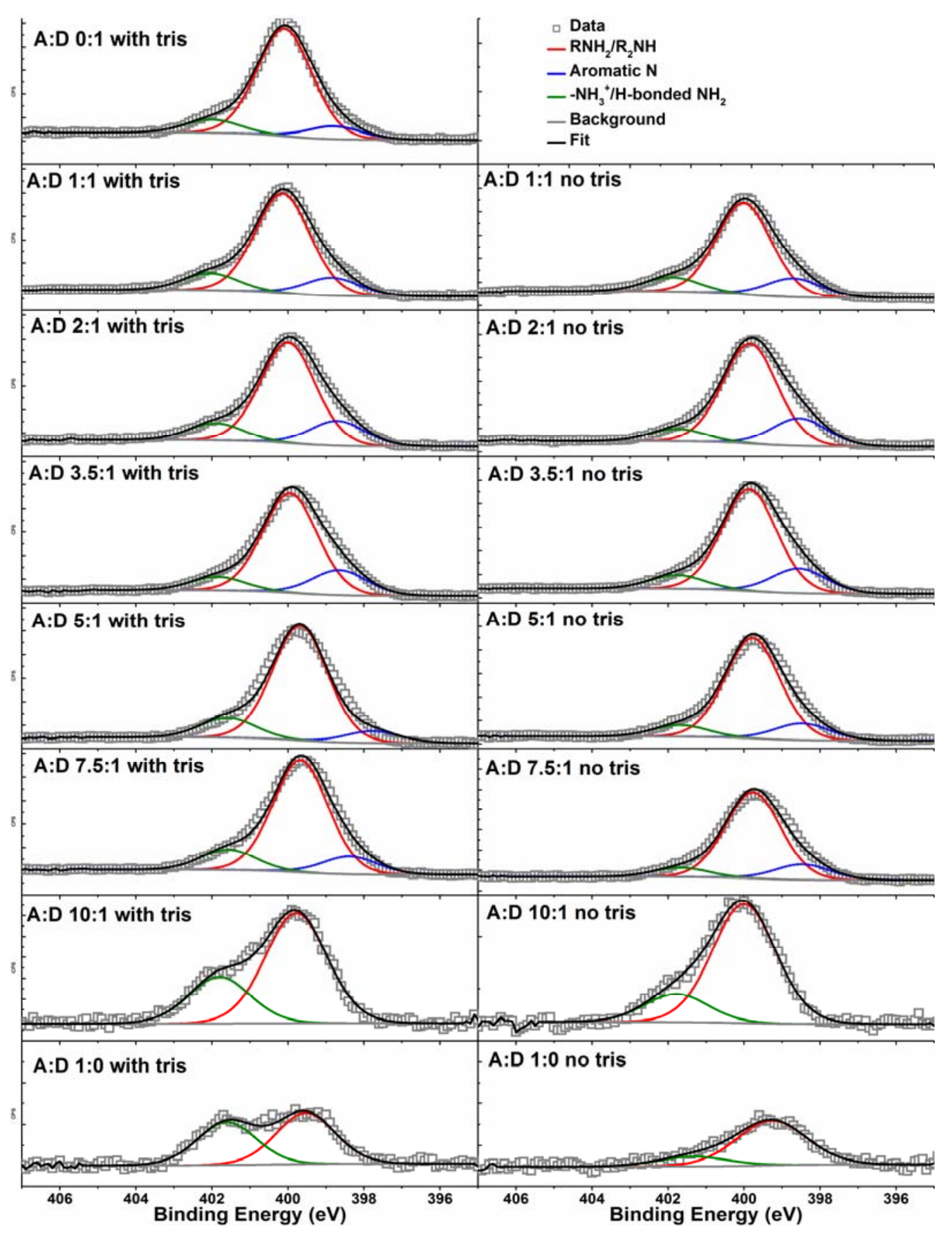

Figure S5. N 1s XPS spectra of all APTES-PDA coatings deposited at different A:D ratios. 


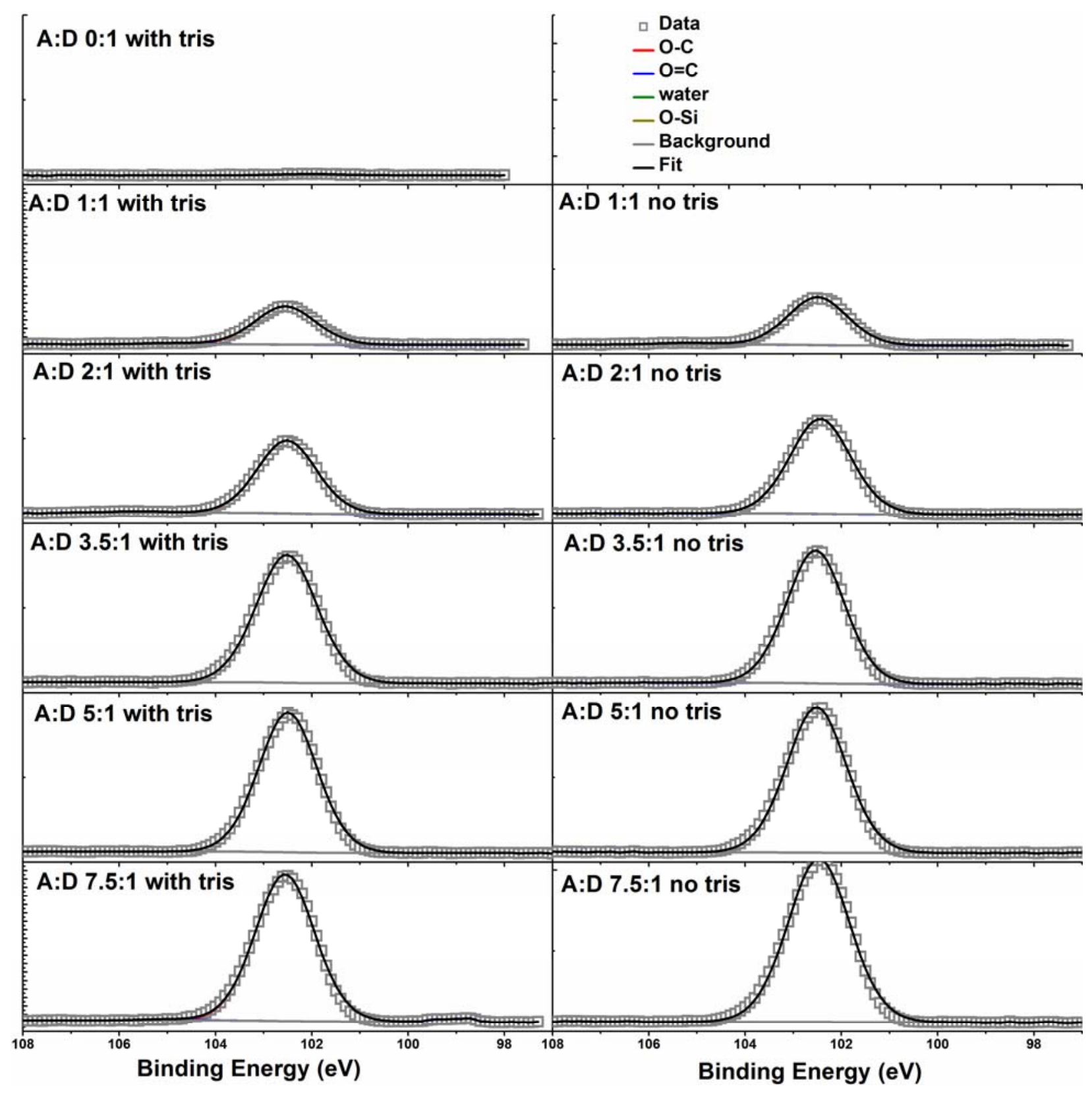

Figure S6. Si 2p XPS spectra of various APTES-PDA coatings deposited at different A:D ratios. 

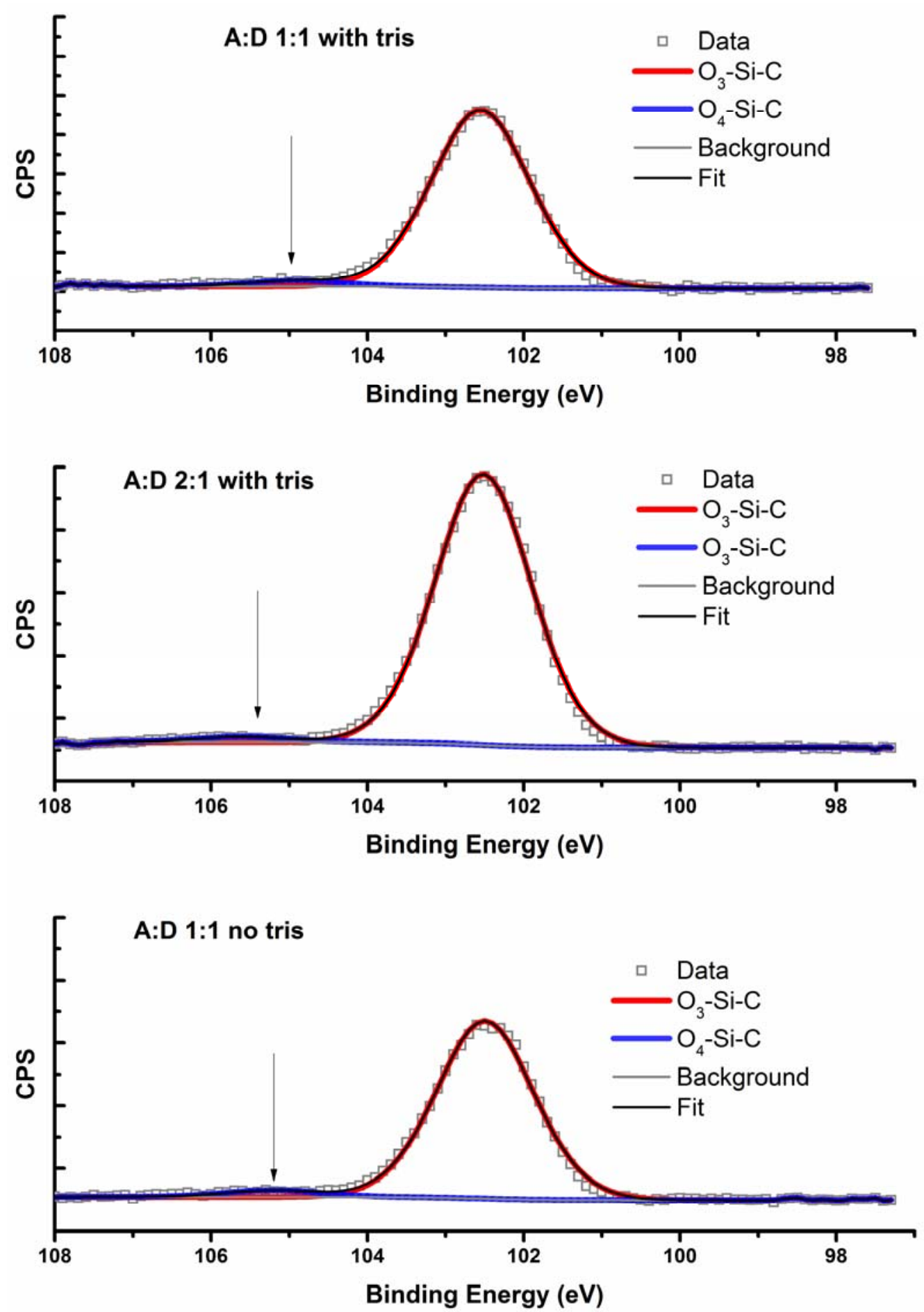

Figure S7. Si 2p XPS spectra for those samples showing $\mathrm{O}_{4}-\mathrm{Si}-\mathrm{C}$ bonding at $\sim 105 \mathrm{eV}$. Arrows indicate the location of this additional peak. 
XPS Data for A:D=3.5:1 without Tris as a Function of Deposition Time
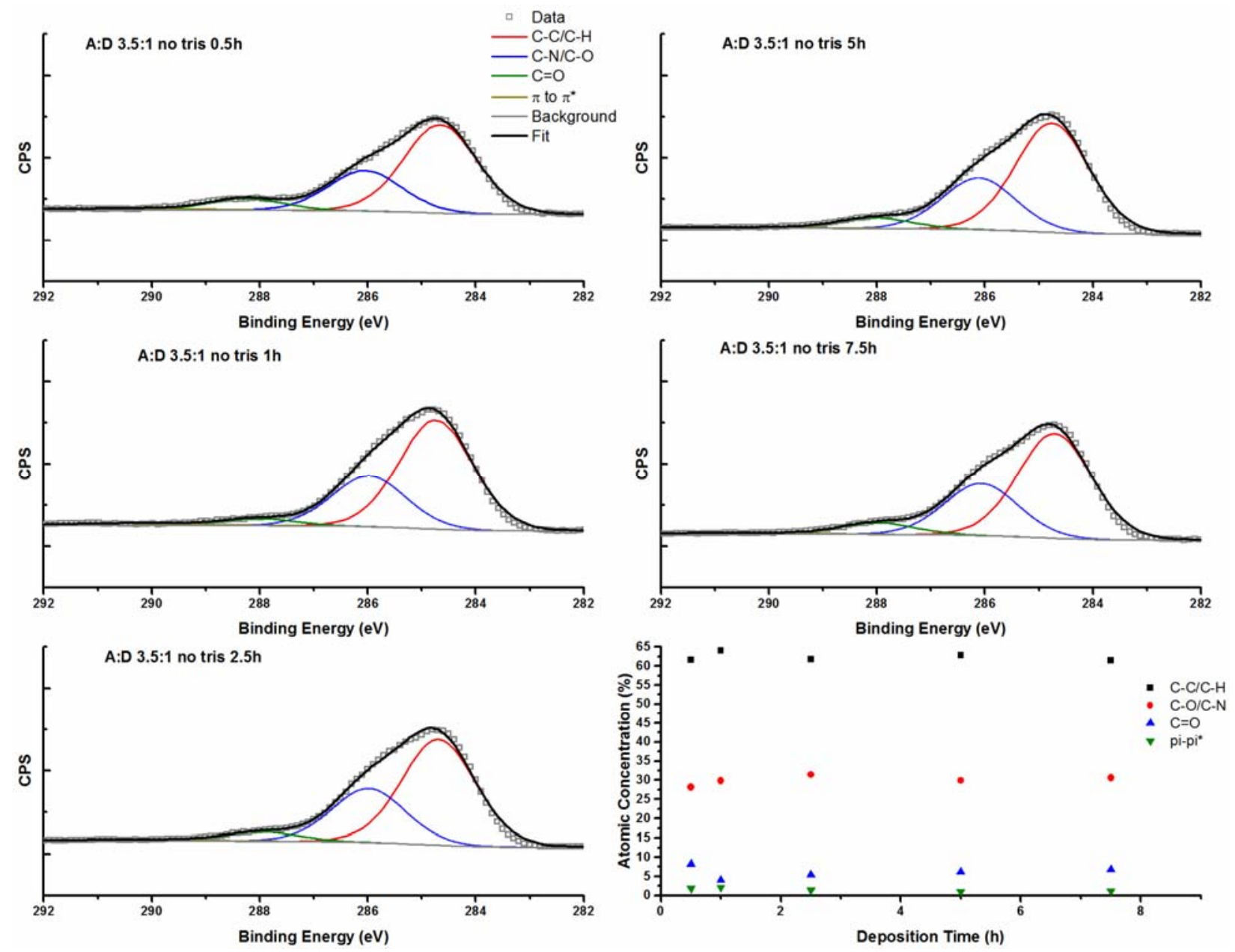

Figure S8. C 1s XPS spectra for 3.5:1 deposition without tris. Lower right plot shows the atomic concentrations of the various $\mathrm{C} 1 \mathrm{~s}$ constituents as a function of deposition time. 

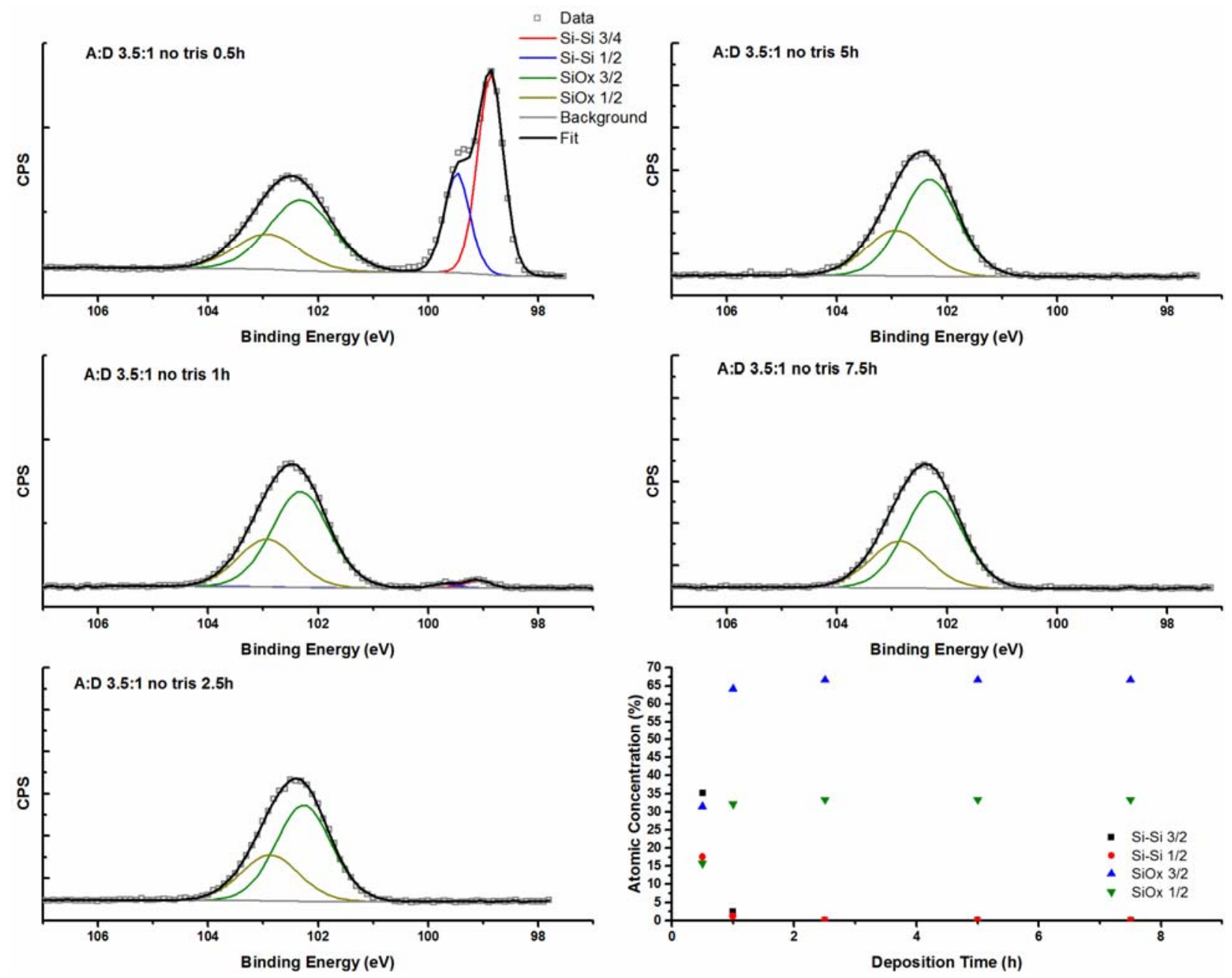

Figure S9. Si 2p XPS spectra for 3.5:1 deposition without tris. Lower right plot shows the atomic concentrations of the various constituents as a function of deposition time. 

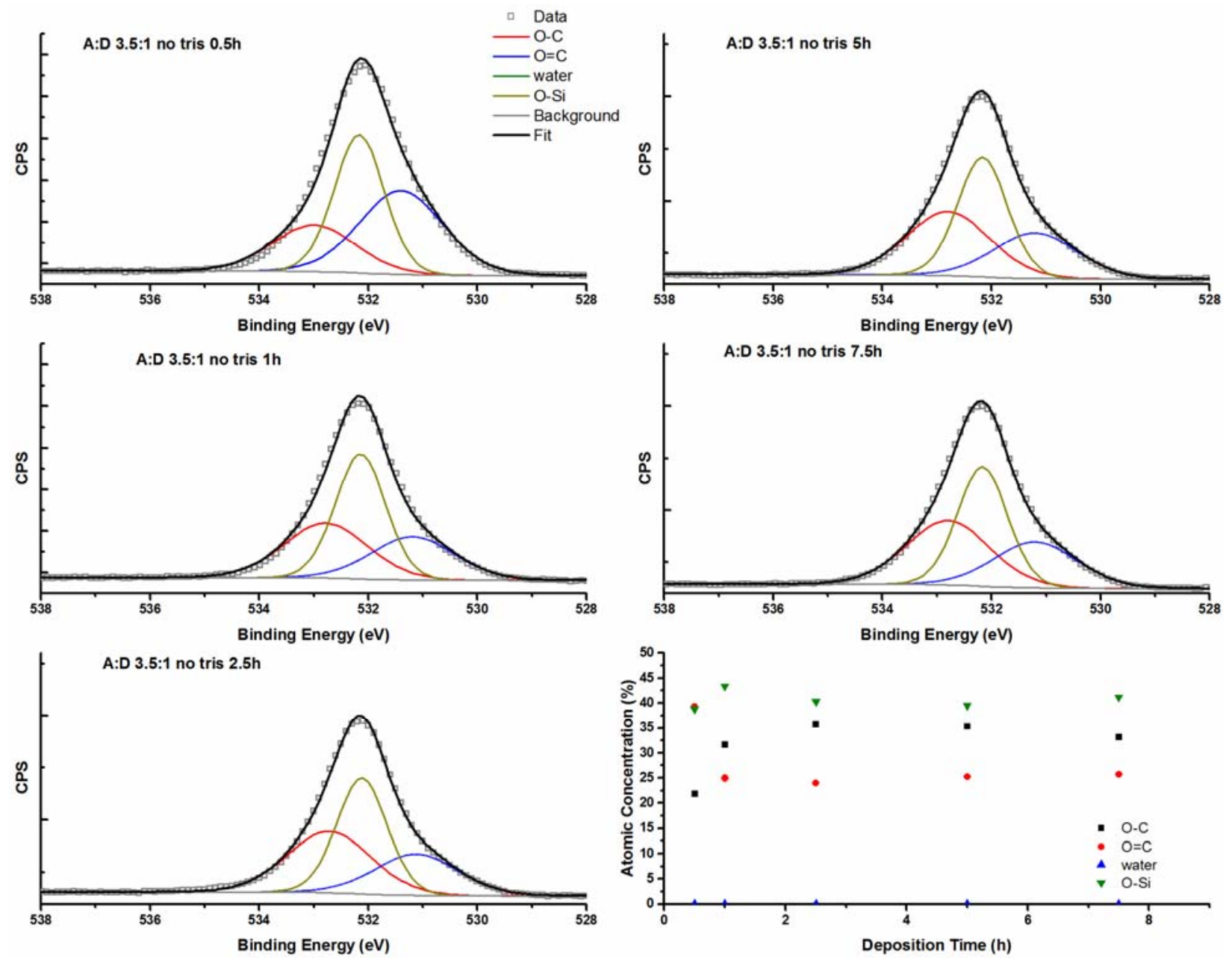

Figure S10. O 1s XPS spectra for 3.5:1 deposition without tris. Lower right plot shows the atomic concentrations of the various constituents as a function of deposition time. 

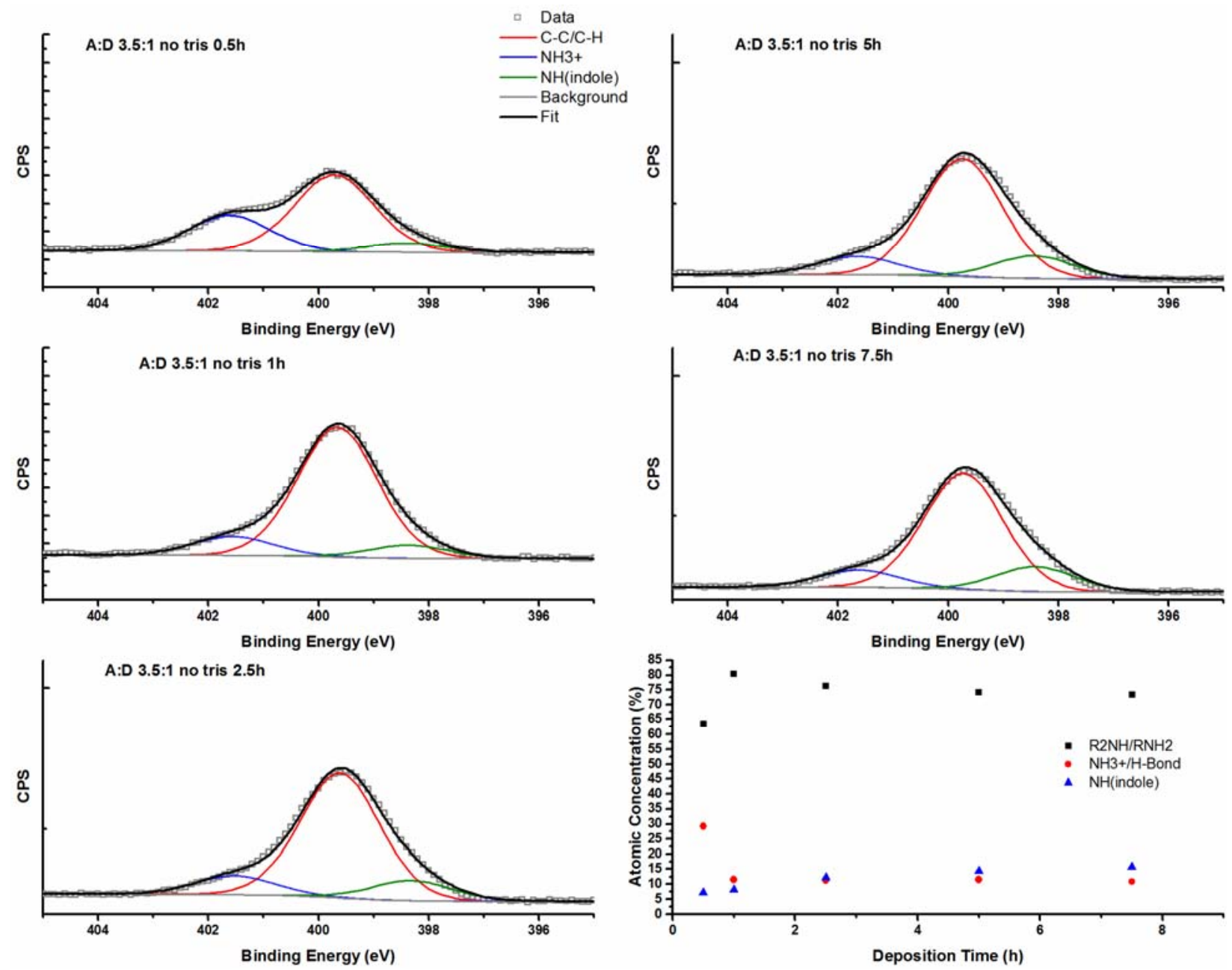

Figure S11. N 1s XPS spectra for 3.5:1 deposition without tris. Lower right plot shows the atomic concentrations of the various constituents as a function of deposition time. 


\section{References}

(1) Jiang, J.; Zhu, L.; Zhu, L.; Zhu, B.; Xu, Y. Langmuir 2011, 27, 14180.

(2) Bernsmann, F.; Ponche, A.; Ringwald, C.; Hemmerle, J.; Raya, J.; Bechinger, B.; Voegel, J.-C.; Schaaf, P.; Ball, V. Journal of Physical Chemistry C 2009, 113, 8234.

(3) Knorr Jr, D. B.; Williams, K. S.; Baril, N. F.; Weiland, C.; Andzelm, J. W.;

Lenhart, J. L.; Woicik, J. C.; Fischer, D. A.; Tidrow, M. Z.; Bandara, S. V.; Henry, N. C. Applied Surface Science 2014, 320, 414.

(4) Min, H.; Girard-Lauriault, P.-L.; Gross, T.; Lippitz, A.; Dietrich, P.; Unger, W. Anal Bioanal Chem 2012, 403, 613.

(5) Acres, R. G.; Ellis, A. V.; Alvino, J.; Lenahan, C. E.; Khodakov, D. A.; Metha, G. F.; Andersson, G. G. Journal of Physical Chemistry C 2012, 116, 6289.

(6) Ding, Y.; Weng, L.-T.; Yang, M.; Yang, Z.; Lu, X.; Huang, N.; Leng, Y. Langmuir 2014, 30, 12258.

(7) Zangmeister, R. A.; Morris, T. A.; Tarlov, M. J. Langmuir 2013, 29, 8619.

(8) Clark, M. B.; Gardella, J. A.; Schultz, T. M.; Patil, D. G.; Salvati, L. Analytical Chemistry 1990, 62, 949.

(9) Chauhan, A. K.; Aswal, D. K.; Koiry, S. P.; Gupta, S. K.; Yakhmi, J. V.; Suergers, C.; Guerin, D.; Lenfant, S.; Vuillaume, D. Applied Physics a-Materials Science \& Processing 2008, 90, 581.

(10) Kannan, B.; Higgins, D. A.; Collinson, M. M. Langmuir 2012, 28, 16091.

(11) Martin, H. J.; Schulz, K. H.; Bumgardner, J. D.; Walters, K. B. Langmuir 2007, 23, 6645 .

(12) Martin, H. J.; Schulz, K. H.; Bumgardner, J. D.; Walters, K. B. Applied Surface Science 2008, 254, 4599.

(13) Thøgersen, A.; Selj, J. H.; Marstein, E. S. Journal of The Electrochemical Society 2012, 159, D276.

(14) Kallury, K. M. R.; Krull, U. J.; Thompson, M. Analytical Chemistry 1988, 60, 169.

(15) Moon, J. H.; Kim, J. H.; Kim, K.; Kang, T. H.; Kim, B.; Kim, C. H.; Hahn, J. H.; Park, J. W. Langmuir 1997, 13, 4305. 